\title{
Psycho-Social Hazards for Staff in Geriatrics and Geriatric Psychiatry
}

\author{
Philippe Thomas', Remy Billon², Jean Albert Chaumier3', Geraldine Barruche1, \\ Cyril Hazif Thomas ${ }^{4}$ \\ ${ }^{1}$ Geriatric Psychiatry Department, University Hospital Esquirol, Limoges, France \\ ${ }^{2}$ Department of Geriatrics, Centre Hospitalier St Louis, La Rochelle, France \\ ${ }^{3}$ Department of Geriatrics, Centre Hospitalier Hôpitaux Sud Charente, Barbezieux, France \\ ${ }^{4}$ Geriatric Psychiatry Department, University Hôpital de Bohars, Brest, France \\ Email: philippe.thomas.2008@orange.fr
}

Received 19 December 2013; revised 13 January 2014; accepted 21 January 2014

Copyright (C) 2014 by authors and Scientific Research Publishing Inc.

This work is licensed under the Creative Commons Attribution International License (CC BY).

http://creativecommons.org/licenses/by/4.0/

(c) (i) Open Access

\section{Abstract}

Context: Exposure to burnout of staff involved with elderly patients is dependent on many factors either personal or linked to the professional environment. Social stress and systemic problems created particularly by difficulties inherent in the French hospital management system and the way people feel it, lead to a risk of burnout. One illustration of this is the rise in suicides at work. Quality of life at work, harassment and psycho-social risks are intimately linked. Affective factors, such as suffering for the medical carers in response to the distress of their patients aggravate the risk of burnout. Methods: We have evaluated these parameters using a self-filled questionnaire form sent to all staff and filled in by computer, anonymously, in 4 establishments, in December 2012 and over the first semester of 2013. After the three factors studied by the ProQOL scale of quality of life at work, to do with burnout, satisfaction compassion and fatigue compassion, 5 other questions were added, connected with a feeling of harassment and several social and demographic matters. Burnout risk was retained on reaching a threshold of $\mathbf{3 0}$ for this ProQOL scale item. Results: After multivariate analysis including the parameters of the Stamm scale, harassment and the socio-demographic factors studied, (age, sex, seniority, profession, and work departments) 4 factors are significantly associated with the risk of burnout, one negatively, compassion satisfaction, three positively, compassion fatigue, harassment experience and seniority. Conclusions: The risk of burnout is linked to subjective factors - the way quality of life at work is perceived and harassment experienced. Some professions, such as nurses, are particularly exposed and require these risk factors to be foreseen.

\section{Keywords}

Burnout; Compassion Satisfaction, Compassion Fatigue, Harassment, Caregiver; Medical Doctor, 


\section{Geriatric Psychiatry, Geriatrics, Working Conditions}

\section{Introduction}

Staff working in geriatric psychiatry is exposed to the violence of patients' behavioral disorders which is a source of secondary traumatisms and undermines empathy [1]-[4]. Confronted with the aggressiveness of a patient made vulnerable by dementia, the caregiver sometimes goes through feelings of guilt and failure as to his care giving [5] [6]. Cognitive disorders reduce the scope of interrelations. So, it is logical that staff working in geriatric psychiatry should find themselves particularly exposed to burnout [7]-[9]. Exposure of staff working with elderly patients depends on multiple personal factors or factors linked to their professional environment. Social stress and systemic problems arising particularly from ever-more pernickety new legal legislation frameworks, and management sensitivity, push staff in the direction of burnout, one illustration of which is an increase of the risk of suicide at work [10]. Harassment and geriatric psychiatry risks are intimately connected with the quality of work life, without being the only factors. The risk of burnout is particularly serious geriatric psychiatry and linked to objective factors, the burdens of working with dependent, sometimes dying patients, communication difficulties when cognitive disorder sets in, violence of the patients' behavioral patterns, excessive responsibility, and professional isolation [11]. Subjective factors intervene: the way the quality of work life is perceived, suffering that mirrors that of the patients (vicarious traumatization) or feelings of moral harassment [12]-[15]. Certain professions are particularly exposed and call for closer study of risk factors and ways of prevention. The act of helping a person experiencing suffering is not a neutral one for a health professional. Compassion for a patient may lead to satisfaction or be a source of fatigue, even exhaustion [16]-[18]. The helper may live the help experience as a reminiscence of some earlier traumatism or undergo secondary traumatic stress because of difficulties encountered at work. We are looking at the register or extent of work life quality of caregivers in this study which is therefore not exhaustive of burnout factors.

\section{Methods}

We have evaluated these parameters using a self-filled questionnaire form sent to all voluntary staff in our services (Limoges, Brest, La Rochelle, Hospitals in South Charente) and 21 other doctors working in geriatric psychiatry units in France. The study began only after explaining its raison d'être and asking the opinion of the hospital authorities concerned, particularly their ethics committees. The forms were filled in as anonymously provided computerized data gathered from 4 establishments that look after elderly people: Geriatric Psychiatry, Centre Hospitalier Esquirol, Limoges and Centre Hospitalier Bohars, Brest; Geriatrics(short term and long term wards), Centre Hospitalier St Louis, La Rochelle and Nursing Home, Centre Hospitalier Hôpitaux South Charente, over the first semester of 2013. All these centers take into their care patients aged over 80. Geriatric psychiatry departments keep patients in for average lengths of time comparable to short stay in geriatric departments, i.e. two to four weeks, but they additionally have to cope with a high number of patients displaying behavioral disorder connected to dementia (70\%) or past psychoses. Patients in nursing homes or long stay geriatric centers represent more than $80 \%$ of dementia cases but long stay cases are more seriously dependent.

For a medical caregiver, quality of working life depends on the satisfaction or the fatigue encountered in situations where patients in distress are taken in charge. One of the measures of this quality of work life is Stamm's Professional Quality of Life Scale (ProQOL) [19]. The ProQOL is the most commonly used measure of the negative and positive effects of helping others who experience suffering and/or trauma. Of the 100 published research papers on compassion fatigue, secondary traumatic stress and vicarious traumatization, nearly half have utilized the ProQOL or one of its earlier versions. The ProQOL has sub-scales for compassion satisfaction, burnout and compassion fatigue. The measure has been in use since 1995. There have been several revisions. The ProQOL 5 is the current French version used in this study.

The Quality of Life Scale puts 10 questions bearing respectively on Burnout risk, satisfaction compassion, and fatigue compassion. Evaluation made by the staff established the marking scale: $1=$ Never, $2=$ rarely, $3=$ Sometimes, $4=$ often, $5=$ Very often. When the document was computer composed, some of the questions were put in a way to invert this scale, (Questions 1 and 4, 15 and 17, 29) on Stamm's instructions. A zero rating, unmodified should the scale be inverted, was kept for unanswered questions. 
According to Stamm's data [19], questions 3, 6, 12, 16, 18, 20, 22, 24, 27, 30 explored compassion satisfaction, questions $1,4,8,10,15,17,19,21,26,29$ burnout risk and questions 2, 5, 7, 9, 11, 13, 14, 23, 25, 28 compassion fatigue. The total of the marks in a given category gives the category score. Burnout, satisfaction compassion, and fatigue compassion thresholds were 30 on the Stamm's ProQOL scale. After the three factors studied by the ProQOL scale, 5 other questions were added, connected to feelings of harassment such as "things are held against me about my work as a helper that have got nothing to do with what I do professionally"; "I felt put down, humiliated, by someone above me at a meeting"; "I feel well backed by the hierarchy in my work as a helper"*; "my work colleagues stand by me when I am in trouble"*, "I do not feel personally respected at work". The same marking system as for Stamm was adopted with the scale of marks for questions designated with an asterisk, *, inverted. Harassment risk was retained with a score of 15 for these particular questions, as against 30 on the Stamm's scale.

The questionnaire also contained a few questions of a social and demographic orientation. Populations of workers in the social and the administrative services, who revealed few statistical differences between them, were regrouped into a single social-administrative category in order for their statistics to be sufficient for analysis purposes. All categories of geriatric psychiatry staff from whatever hospital were regrouped for the statistical study.

The statistical tests used included Pearson Chi-square, the Student's t test, and Pearson's correlation matrix. A multivariate logistic regression for the risk of burnout was conducted taking into account the marks for compassion fatigue, compassion satisfaction, harassment experience and the social-demographic factors studied, (age, sex, seniority, profession, work departments, full-time/part-time...). The tests were carried out using a Systat $\mathrm{s} / \mathrm{w}$. by a bio-statistician who is co-author of this paper (RB).

\section{Results}

Four hundred forms were completed, corresponding to approximately $58 \%$ of overall staff numbers liable to answer the questionnaires. $98.6 \%$ of the 30 items of the Stamm's scale and the 5 questions on harassment were filled in. 167 people were working on psychiatrics of the elderly (Table 1), 67 in short term geriatric stay, and the rest in retirement homes $(n=142)$ or in long stay $(n=24)$.

Burnout scores (Table 2) were lower in geriatric and long stay units than in psycho-geriatrics or in retirement homes (t Test; $\mathrm{p}<0.01$ ). 94 people out of 400 caregivers were exposed to burnout risk (Table 3 \& Table 4) of which 50 out of the 167 posted to psycho-geriatric units (Pearson's Chi-square $=13.1 ; \mathrm{p}=0.01$ ). Medical secretaries (8/19) and health officers (4/11) are particularly exposed, followed by nurses (37/117) and doctors (11/53).

The care-giver population exposed to burnout risk (Table 5) scores more heavily in compassion fatigue, is more vulnerable to harassment, is in an older age-group and has greater seniority. As opposed to this, they score lower on compassion satisfaction.

A correlation matrix was realized from the quantitative data obtained (Table 6). Age and seniority are feebly co-related to the Stamm scale burnout score (respectively, $\mathrm{R}=0.203$ and $0.275 ; \mathrm{p}<0.01$ ). This score is negatively but strongly co-related to the compassion satisfaction score $(\mathrm{R}=-0.639$; $\mathrm{p}<0.001)$, positively and strongly to the score for harassment items, $(\mathrm{R}=-0.591 ; \mathrm{p}<0.001)$, and the compassion fatigue score $(\mathrm{R}=-0.622 ; \mathrm{p}<$ 0.001). The Odd ratio for burnout exposure, when a person is in danger of harassment, is 10.02 (chi2 = 81.27; interval 5.76 - 17.42). Multivariate analysis (Table 7) shows three factors are significantly linked to the risk of burnout, one negatively, compassion satisfaction, $(\mathrm{t}=-7.30$; $\mathrm{p}<0.001)$, two positively, compassion fatigue, $(\mathrm{t}=$ 0.558, $\mathrm{p}<0.001)$, and harassment feelings $(\mathrm{t}=0.309$, $\mathrm{p}=0.002)$.

Figure 1 shows the evolution of scores for compassion fatigue and compassion satisfaction according to whether seniority is higher or lower than 10 years. Some professions make no change to these scores, psychologists and social-administrative workers. However, in contrast, major significant variations occur in the Student Test results, for the two parameters which are marked in order of serious worsening due to seniority, for health care assistants, nurses and medical doctors. Seniority is better integrated and experienced by secretaries who see a serious lessening of their compassion fatigue whereas their compassion satisfaction remains the same; and nursing supervisors, who significantly improve their compassion satisfaction and, to an insignificant degree, their compassion fatigue.

\section{Discussion}

The goal of this paper is to determine the quality of life at work and psycho-social hazards for staff in Geriatrics 
Table 1. Characteristics of the caregivers’ populations. M/F: Male/Female.

\begin{tabular}{|c|c|c|c|c|c|c|}
\hline & Age & Years of service & Burnout & $\begin{array}{l}\text { Compassion } \\
\text { satisfaction }\end{array}$ & $\begin{array}{l}\text { Compassion } \\
\text { fatigue }\end{array}$ & Harassement \\
\hline $\begin{array}{c}\text { Nurses } \\
\mathrm{N}=117 \mathrm{M} / \mathrm{F}: 27 / 90\end{array}$ & $38.9 \pm 10.3$ & $12.5 \pm 11.0$ & $26.0 \pm 7.3$ & $35.1 \pm 7.5$ & $23.1 \pm 5.9$ & $11.3 \pm 4.4$ \\
\hline $\begin{array}{c}\text { Health assistants } \\
\mathrm{N}=172 \mathrm{M} / \mathrm{F}: 14 / 158\end{array}$ & $38.1 \pm 10.2$ & $10.6 \pm 8.4$ & $24.8 \pm 5.6$ & $37.4 \pm 6.7$ & $22.4 \pm 6.3$ & $10.3 \pm 3.4$ \\
\hline $\begin{array}{c}\text { Medical doctors } \\
\mathrm{N}=53 \mathrm{M} / \mathrm{F}: 33 / 20\end{array}$ & $38.3 \pm 10.8$ & $11.0 \pm 9.9$ & $23.6 \pm 6.6$ & $36.9 \pm 8.2$ & $24.6 \pm 8.6$ & $10.7 \pm 4.1$ \\
\hline $\begin{array}{c}\text { Secretaries } \\
\mathrm{N}=19 \mathrm{M} / \mathrm{F}: 0 / 19\end{array}$ & $39.7 \pm 8.5$ & $14.2 \pm 11.1$ & $28.6 \pm 9.2$ & $33.9 \pm 6.4$ & $25.7 \pm 8.2$ & $12.4 \pm 4.4$ \\
\hline $\begin{array}{l}\text { Socio-administrative workers } \\
\qquad \mathrm{N}=13 \mathrm{M} / \mathrm{F}: 8 / 8\end{array}$ & $40.3 \pm 11.7$ & $13.0 \pm 10.3$ & $19.7 \pm 3.3$ & $43.1 \pm 2.4$ & $17.1 \pm 4.8$ & $9.6 \pm 2.8$ \\
\hline $\begin{array}{l}\text { Nursing supervisors } \\
\mathrm{N}=11 \mathrm{M} / \mathrm{F}: 2 / 9\end{array}$ & $46.3 \pm 8.8$ & $12.4 \pm 8.9$ & $28.6 \pm 6.4$ & $36.3 \pm 6.6$ & $27.6 \pm 6.6$ & $12.4 \pm 4.1$ \\
\hline
\end{tabular}

Table 2. Characteristics of the caregivers' groups and mean scores according to their place of work.

\begin{tabular}{ccccccc}
\hline & Age & Years of service & Burnout & $\begin{array}{c}\text { Compassion } \\
\text { satisfaction }\end{array}$ & $\begin{array}{c}\text { Compassion } \\
\text { fatigue }\end{array}$ & Harassement \\
\hline $\begin{array}{c}\text { Nursing home } \\
\text { N = 142 } \\
\text { Geriatrics } \\
\text { N }=67\end{array}$ & $38.9 \pm 10.6$ & $11.5 \pm 9.0$ & $25.5 \pm 6.6$ & $36.1 \pm 7.7$ & $22.9 \pm 6.7$ & $10.9 \pm 3.9$ \\
$\begin{array}{c}\text { GeriatricPsychiatry } \\
\text { N = 167 }\end{array}$ & $38.7 \pm 10.1$ & $11.5 \pm 10.0$ & $23.8 \pm 5.4$ & $36.5 \pm 6.2$ & $21.6 \pm 5.3$ & $9.7 \pm 3.0$ \\
$\begin{array}{c}\text { Long term care } \\
\text { N = } 24\end{array}$ & $37.4 \pm 10.5$ & $8.2 \pm 7.0$ & $23.8 \pm 5.4$ & $38.9 \pm 5.4$ & $24.4 \pm 5.7$ & $11.5 \pm 4.2$ \\
\hline
\end{tabular}

Table 3. Risk of Burnoutaccording to the places of work.Pearson Chi-square: 13.179. $\mathrm{p}=0.010$.

\begin{tabular}{ccccc}
\hline & Geriatrics & Nursing home & Psycho-geriatrics & Long term care \\
\hline No risk of burnout $\mathrm{N}=306$ & 60 & 109 & 117 & 50 \\
Risk of Burnout $\mathrm{N}=94$ & 7 & 33 & 4 \\
Total & 67 & 142 & 167 & 24 \\
\hline
\end{tabular}

Table 4. Number of persons with aburnout risk.Pearson Chi-square: 16.154. $\mathrm{p}=0.024$.

\begin{tabular}{ccccccc}
\hline 1 & Nurses & Secretaries & $\begin{array}{c}\text { Health } \\
\text { assistants }\end{array}$ & $\begin{array}{c}\text { Medical } \\
\text { doctors }\end{array}$ & $\begin{array}{c}\text { Psychologists } \\
\text { administrative } \\
\text { workers }\end{array}$ \\
supervisors \\
Cases without a risk of burnout: $\mathrm{N}=306$ & 80 & 11 & 141 & 42 & 12 & 13 \\
Cases without a risk of burnout: $\mathrm{N}=94$ & 37 & 8 & 31 & 11 & 3 & 0 \\
Total & 117 & 19 & 172 & 53 & 15 & 13 \\
\hline
\end{tabular}

Table 5. Scores of the populations at risk of burnout. T test: $\mathrm{p}<0.001$ for all parameters.

\begin{tabular}{|c|c|c|c|c|c|c|}
\hline & Age & Years of service & Burnout & $\begin{array}{l}\text { Compassion } \\
\text { satisfaction }\end{array}$ & $\begin{array}{c}\text { Compassion } \\
\text { fatigue }\end{array}$ & Harassement \\
\hline Cases with a risk of burnout: $\mathrm{N}=94$ & $41.6 \pm 9.9$ & $15.3 \pm 10.5$ & $29.3 \pm 7.3$ & $34.4 \pm 4.3$ & $28.9 \pm 6.9$ & $14.3 \pm 4.0$ \\
\hline Cases without a risk of burnout: $\mathrm{N}=306$ & $37.7 \pm 10.2$ & $10.2 \pm 9.0$ & $38.8 \pm 5.4$ & $22.3 \pm 4.2$ & $21.2 \pm 5.1$ & $9.7 \pm 3.2$ \\
\hline
\end{tabular}

and Geriatric Psychiatry practices. The exposure to burnout of staff involved with elderly patients is dependent on many factors either personal or linked to the professional environment. Social stress, systemic problematic created particularly by difficulties inherent in the French hospital management system and the way it is felt, lead to a risk of burnout, one illustration of which is the rise in suicides at work. Quality of life at work, harassment and psy- 
Table 6. Correlationmatrix of the quantitative parameters under study.

\begin{tabular}{cccccc}
\hline & Age & Years of service & Burnout & Compassion satisfaction & Compassion fatigue \\
\hline Age & 1.000 & & & & \\
Years of service & 0.736 & 1.000 & & & \\
Burnout & 0.203 & 0.275 & 1.000 & 1.000 & 1.000 \\
Compassion satisfaction & -0.225 & -0.267 & -0.639 & -0.449 & 0.527 \\
Compassion fatigue & 0.197 & 0.189 & 0.622 & -0.530 & 0.591 \\
Harassement & 0.174 & 0.260 & & \\
\hline
\end{tabular}

Table 7. Multivariate logistic regression Risk of burnout (Burnout’s score $\geq 30$ ).

\begin{tabular}{|c|c|c|c|}
\hline Effect & Coefficient & $\mathrm{t}$ & $\mathrm{P}$ \\
\hline CONSTANT & 0.478 & 2.318 & 0.021 \\
\hline Compassion satisfaction & -0.021 & -7.306 & 0.000 \\
\hline Compassion fatigue & 0.017 & 5.588 & 0.000 \\
\hline Harassement & 0.017 & 3.091 & 0.002 \\
\hline
\end{tabular}

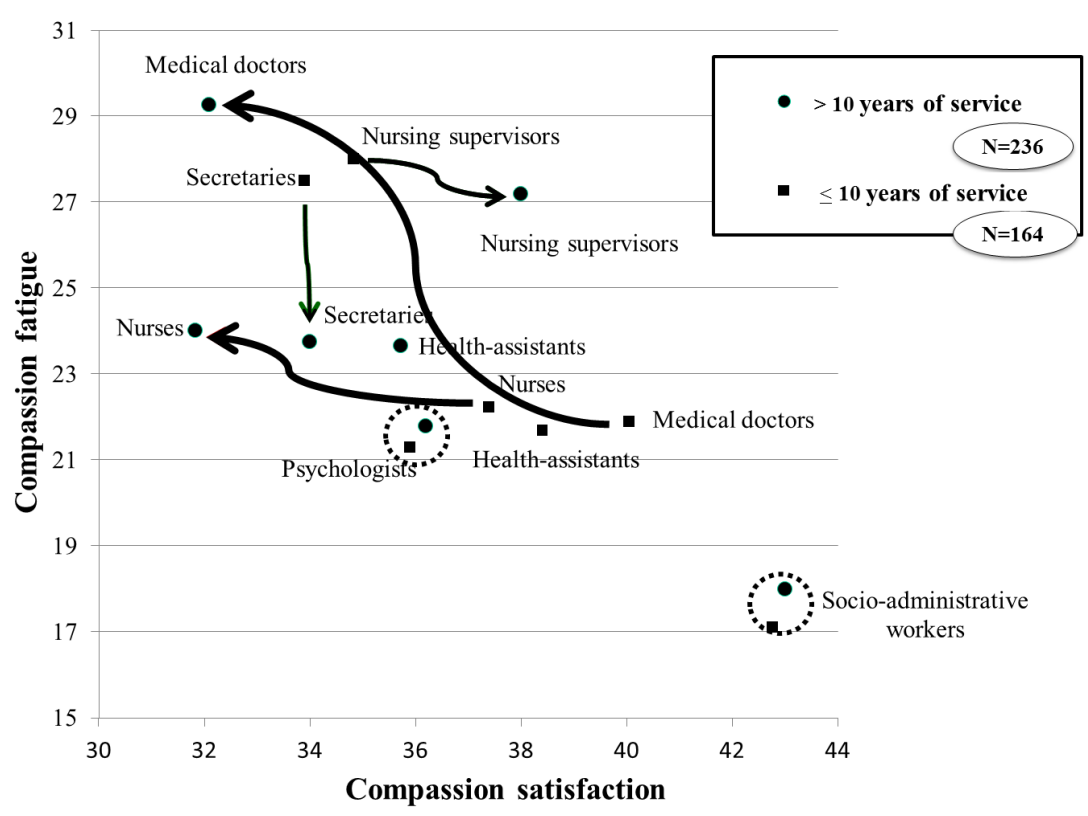

Figure 1. Variation of compassion fatigue and compassion satisfaction according to the number of service years.

cho-social risks are intimately linked. Therefore, affective factors, such as suffering for the medical careers in response to the distress of their patients aggravate the risk of burnout. We evaluated these parameters using a self-filled questionnaire form sent to all staff and filled in by computer, anonymously, in 4 establishments, in December 2012 and over the first semester of 2013. After the three factors studied by the ProQOL scale of quality of life at work, to do with burnout, satisfaction compassion and fatigue compassion, 5 other questions were added, connected with a feeling of harassment and several social and demographic matters. Burnout risk was retained on reaching a threshold of 30 for this ProQOL scale items [19]. Results based on this methodology showed that the after multivariate analysis including the parameters of the Stamm's scale, harassment and the socio-demographic factors studied, (age, sex, seniority, profession, work departments), 4 factors are significantly associated with the risk of burnout, one negatively, compassion satisfaction, three positively, compassion fatigue, harassment experience and seniority. Conclusions based on this study indicate that the risk of burnout is linked to subjective factors - the way quality of life at work is perceived and harassment experienced. Some professions, such as nurses, are particularly exposed and require these risk factors to be foreseen. 
Health care professionals, particularly in geriatrics and psycho-geriatrics, are specially exposed to the risk of burnout [17] [20]-[22]. Caregivers are exposed to the violence of demented patients, source of secondary trauma, undermining empathy. When caregivers are confronted by aggressiveness from one of their patients, they may experience feelings of guilt or inefficiency in their work of care giving. This is one of the reasons why staff employed in geriatric psychiatry is particularly exposed to the risk of burnout. Of course, there may be other factors: perhaps personal or associated with a work v. private life conflict, cases that we have not dealt with here, and which might be a further approach for this study [23]. This study shows, however, that secretaries, nursing supervisors, and doctors also, are exposed to the risk. Burnout includes objective factors not dealt with in this study centered on subjectivity particularly related to compassion suffering arising from caring for a person in distress. Other approaches exist for this presentation. For example, a response level of 58\% for the overall categories of staff liable to reply to the study and questionnaire is doubtless a high one in view of the diversely explainable absenteeism. Yet, we cannot presume what would have been the answers from people who remained silent to our questionnaire. The terms of the questionnaire are expressed in simple words so as to be understood by staff unacquainted with or untrained in technical vocabulary. This fact may have incurred a loss of precision; selected criteria and markers may not always be sufficiently accurate and data gathered from this study need confirming. For these reasons, results are only preliminary.

We have not gone into the psychological state staff was in before answering our questionnaire. Some staff can experience negative effects of secondary exposure without developing a psychological disorder such as a post-traumatic stress disorder. Compassion Fatigue is not a diagnosis. Compassion Satisfaction and Compassion Fatigue can be thought of in simple terms as the positive aspects of helping and the negative aspects of helping, protecting for the first one or triggering psychological disorders for the latter, the burnout. Compassion Fatigue is a descriptive term and it is possible that a person struggling with Compassion Fatigue also has a psychological disorder. For example, people who suffer with burnout may also have a depression. Similarly, people may have a post-traumatic stress disorder or some other mental, emotional or physical disorder that is likely linked to their experience of compassion fatigue.

This study shows that compassion fatigue and harassment feelings run high when there is a burnout risk [13] [14] [24] [25]. On the contrary, compassion satisfaction is then low. We have not presented results showing that when scores of compassion satisfaction are high, burnout risk is low. The Stamm's model proposes the idea of an independent system with these three parameters, with compassion satisfaction counter-balancing the two other [19]. The implementation of work methods in geriatrics and psycho-geriatrics that developed empathy and promoted compassion satisfaction could be a source of quality of life for both carers and patients and might also limit the risks of burnout [26] [27].

Years spent in professional practice spoil empathy with patients and compassion satisfaction [28]-[31] and thereby, in association with other factors such as tiredness due to age, cause exposure to burnout. Nevertheless, it is interesting to notice that nurses supervisors and secretaries get better job satisfaction with seniority. All the professions do not follow the same courses and nurses and doctors find themselves in difficult situations as the years go by [32]. Disillusionment, work repetitiveness and loss of initial enthusiasm and motivation can be underlying [33]. Professional mobility could perhaps be a solution to these problems. Administrative social workers are less geared up than their predecessors in matters of aid to people in distress. That is not the situation of psychologists, who are particularly well equipped to face up to difficult human situations. Training of carers and doctors for help relations could also be a way to forestall burnout [34].

Professional isolation, frequent in retirement homes where numbers of medical carers are often low, is an important factor of burnout. Such isolation may be caused by a form of harassment more and more frequently pinpointed by the courts in this country. The rules of social protection can in such ways be cynically disregarded by moral harassment, difficult to prove, and aiming at forcing an unwanted employee to quit.

Of course, our point is not to regard such manœuvres as being universally applied and many establishments do function with a code of ethics toward their staff. Nevertheless, the cost in human terms is considerable and is translated by an epidemic of suicides at work in France, as is regularly reported in the national Press. On the contrary, burnout is often accompanied by bitter or difficult relations that aggravate the isolation and can lead to interpretations of harassment. The formulation by the staff of expressions or feelings of harassment calls in any case, therefore, for reflection by colleagues and hierarchy if the consequences of possible burnout are to be limited.

Staff working in Geriatric Psychiatry is exposed to the violence of patients' behavioral disorders which is a source of secondary traumatisms and undermines empathy. Confronted with the aggressiveness of a patient made 
vulnerable by dementia, the caregiver sometimes goes through feelings of guilt and failure as to his care giving. Cognitive disorders reduce the scope of interrelations. So, it is logical that staff working in geriatric psychiatry should find themselves particularly exposed to burnout. A national survey published in the Archives of Internal Medicine in 2012 [35] reported that US physicians suffer more burnout than other American workers. The two specialties with the highest percentage of burnout were those that dealt with severely ill patients: emergency medicine and critical care. According to our study, French medical doctor caring for elderly can be involved in psychosocial risks.

\section{Conclusion}

It is as if compassion satisfaction and connected items, such as inter-professional solidarity, and, at a wider level, attentiveness to other people, enabled burnout to be forestalled and feelings of harassment limited [36]. Seniority might, for certain professions, constitute a particular social psychological risk.

\section{Acknowledgements}

The authors wish to thank Stephen Burrough who so graciously contributed to the achievement of this work.

\section{Conflicts of Interests}

The authors declare that they have no conflicts of interests with respect to their authorship or the publication of this article.

\section{References}

[1] Coetzee, S.K. and Klopper, H.C. (2010) Compassion Fatigue within Nursing Practice: A Concept Analysis. Nursing \& Health Sciences, 12, 235-243. http://dx.doi.org/10.1111/j.1442-2018.2010.00526.x

[2] Innes, A., McCabe, L. and Watchman, K. (2012) Caring for Older People with an Intellectual Disability: A Systematic Review. Maturitas, 72, 286-295. http://dx.doi.org/10.1016/j.maturitas.2012.05.008

[3] Carlsson, G., Dahlberg, K., Lutzen, K. and Nystrom, M. (2004) Violent Encounters in Psychiatric Care: A Phenomenological Study of Embodied Caring Knowledge. Issues in Mental Health Nursing, 25, 191-217. http://dx.doi.org/10.1080/01612840490268324

[4] Abendroth, M. and Flannery, J. (2006) Predicting the Risk of Compassion Fatigue: A Study of Hospice Nurses. Journal of Hospice and Palliative Nursing, 8, 346-356. http://dx.doi.org/10.1097/00129191-200611000-00007

[5] Papastavrou, E., Tsangari, H., Karayiannis, G., Papacostas, S., Efstathiou, G. and Sourtzi, P. (2011) Caring and Coping: the Dementia Caregivers. Aging \& Mental Health, 15, 702-711. http://dx.doi.org/10.1080/13607863.2011.562178

[6] Perry, D.C. and Miller, B.L. (2013) Frontotemporal Dementia. Seminars in Neurology, 33, 336-341. http://dx.doi.org/10.1055/s-0033-1359316

[7] Whitebird, R.R., Asche, S.E., Thompson, G.L., Rossom, R. and Heinrich, R. (2013) Stress, Burnout, Compassion Fatigue, and Mental Health in Hospice Workers in Minnesota. Journal of Palliative Medicine, 16, 1534-1539. http://dx.doi.org/10.1089/jpm.2013.0202

[8] Smart, D., English, A., James, J., Wilson, M., Daratha, K. B., Childers, B., et al. (2013) Compassion Fatigue and Satisfaction: A Cross-Sectional Survey among US Healthcare Workers. Nursing \& Health Sciences, 16, 3-10.

[9] Slocum-Gori, S., Hemsworth, D., Chan, W. W., Carson, A. and Kazanjian, A. (2013) Understanding Compassion Satisfaction, Compassion Fatigue and Burnout: A Survey of the Hospice Palliative Care Workforce. Palliative Medicine, 27, 172-178. http://dx.doi.org/10.1177/0269216311431311

[10] Hooper, C., Craig, J., Janvrin, D.R., Wetsel, M.A. and Reimels, E. (2010) Compassion Satisfaction, Burnout, and Compassion Fatigue among Emergency Nurses Compared with Nurses in Other Selected Inpatient Specialties. Journal of Emergency Nursing: JEN: Official Publication of the Emergency Department Nurses Association, 36, 420-427. http://dx.doi.org/10.1016/j.jen.2009.11.027

[11] Romano, J., Trotta, R. and Rich, V.L. (2013) Combating Compassion Fatigue: An Exemplar of an Approach to Nursing Renewal. Nursing Administration Quarterly, 37, 333-336. http://dx.doi.org/10.1097/NAQ.0b013e3182a2f9ff

[12] Laschinger, H.K. and Grau, A.L. (2012) The Influence of Personal Dispositional Factors and Organizational Resources on Workplace Violence, Burnout, and Health Outcomes in New Graduate Nurses: A Cross-Sectional Study. International Journal of Nursing Studies, 49, 282-291. http://dx.doi.org/10.1016/j.ijnurstu.2011.09.004

[13] Yildirim, D. (2009) Bullying among Nurses and Its Effects. International Nursing Review, 56, 504-511. 
http://dx.doi.org/10.1111/j.1466-7657.2009.00745.x

[14] Sa, L. and Fleming, M. (2008) Bullying, Burnout, and Mental Health amongst Portuguese Nurses. Issues in Mental Health Nursing, 29, 411-426. http://dx.doi.org/10.1080/01612840801904480

[15] Sinclair, H.A. and Hamill, C. (2007) Does Vicarious Traumatisation Affect Oncology Nurses? A Literature Review. European Journal of Oncology Nursing: The Official Journal of European Oncology Nursing Society, 11, 348-356. http://dx.doi.org/10.1016/j.ejon.2007.02.007

[16] Gallagher, R. (2013) Compassion Fatigue. Canadian Family Physician Medecin de Famille Canadien, 59, $265-268$.

[17] Adams, R.E., Boscarino, J.A. and Figley, C.R. (2006) Compassion Fatigue and Psychological Distress among Social Workers: A Validation Study. The American Journal of Orthopsychiatry, 76, 103-108. http://dx.doi.org/10.1037/0002-9432.76.1.103

[18] Figley, C.R. (2002) Compassion Fatigue: Psychotherapists’ Chronic Lack of Self Care. Journal of Clinical Psychology, 58, 1433-1441. http://dx.doi.org/10.1002/jclp.10090

[19] Stamm, B.H. (2010) ProQOL. Comprehensive Bibliography of the Effect of Caring for Those Who Have Experienced Extremely Stressful Events and Suffering.

[20] Boscarino, J.A., Kirchner, H.L., Hoffman, S.N., Sartorius, J., Adams, R.E. and Figley, C.R.(2011) A Brief Screening Tool for Assessing Psychological Trauma in Clinical Practice: Development and Validation of the New York PTSD Risk Score. General Hospital Psychiatry, 33, 489-500. http://dx.doi.org/10.1016/j.genhosppsych.2011.06.001

[21] Beck, C.T. (2011) Secondary Traumatic Stress in Nurses: A Systematic Review. Archives of Psychiatric Nursing, 25, 1-10. http://dx.doi.org/10.1016/j.apnu.2010.05.005

[22] Bride, B.E. (2007) Prevalence of Secondary Traumatic Stress among Social Workers. Social Work, 52, 63-70. http://dx.doi.org/10.1093/sw/52.1.63

[23] Dyrbye, L.N., Sotile, W., Boone, S., West, C. P., Tan, L., Satele, D., et al. (2014) A Survey of U.S. Physicians and Their Partners Regarding the Impact of Work-Home Conflict. Journal of General Internal Medicine, 29, 155-161. http://dx.doi.org/10.1007/s11606-013-2581-3

[24] Johnson, S.L. (2009) International Perspectives on Workplace Bullying among Nurses: A Review. International Nursing Review, 56, 34-40. http://dx.doi.org/10.1111/j.1466-7657.2008.00679.x

[25] Lowenstein, L.F. (2013) Bullying in Nursing and Ways of Dealing with It. Nursing Times, 109, 22-25.

[26] Tehrani, N. (2010) Compassion Fatigue: Experiences in Occupational Health, Human Resources, Counselling and Police. Occupational Medicine, 60, 133-138. http://dx.doi.org/10.1093/occmed/kqp174

[27] Tehrani, N. (2007) The Cost of Caring-The Impact of Secondary Trauma on Assumptions, Values and Beliefs. Counselling Psychology Quarterly, 20, 325-339. http://dx.doi.org/10.1080/09515070701690069

[28] Newton, B.W., Barber, L., Clardy, J., Cleveland, E. and O’Sullivan, P. (2008) Is There Hardening of the Heart during Medical School? Academic Medicine: Journal of the Association of American Medical Colleges, 83, 244-249.

[29] Newton, B. W., Savidge, M. A., Barber, L., Cleveland, E., Clardy, J., Beeman, G., et al. (2000) Differences in Medical Students' Empathy. Academic Medicine: Journal of the Association of American Medical Colleges, 75, 1215. http://dx.doi.org/10.1097/00001888-200012000-00020

[30] Hojat, M., Vergare, M.J., Maxwell, K., Brainard, G., Herrine, S.K., Isenberg, G.A., et al. (2009) The Devil Is in the Third Year: A Longitudinal Study of Erosion of Empathy in Medical School. Academic Medicine: Journal of the Association of American Medical Colleges, 84, 1182-1191.

[31] Branch Jr., W.T., Davis, K. and Weng, M. (2012) Teaching Compassion. Patient Education and Counseling, 89, 3-4. http://dx.doi.org/10.1016/j.pec.2012.03.013

[32] Dyrbye, L.N., Varkey, P., Boone, S.L., Satele, D.V., Sloan, J.A. and Shanafelt, T.D. (2013) Physician Satisfaction and Burnout at Different Career Stages. Mayo Clinic Proceedings, 88, 1358-1367. http://dx.doi.org/10.1016/j.mayocp.2013.07.016

[33] Black, H.K. (2004) Moral Imagination in Long-Term Care Workers. Omega, 49, 299-320.

[34] Longmaid, H.E., Branch Jr., W.T. and Rider, E.A. (2013) Compassion: Necessary But Not Sufficient. Academic Medicine: Journal of the Association of American Medical Colleges, 88, 1197.

[35] Shanafelt, T.D., Boone, S., Tan, L., Dyrbye, L.N., Sotile, W., Satele, D., et al. (2012) Burnout and Satisfaction with Work-Life Balance among US Physicians Relative to the General US Population. Archives of Internal Medicine, 172, 1377-1385. http://dx.doi.org/10.1001/archinternmed.2012.3199

[36] Zimmermann, M. (2013) Integrating Medical Humanities into a Pharmaceutical Care Seminar on Dementia. American Journal of Pharmaceutical Education, 77, 16. http://dx.doi.org/10.5688/ajpe77116 